\title{
DEDDNTE

\section{3) Promoção de hábitos saudáveis com idosos diabéticos: utilização de grupos operativos como intervenção terapêutica}

Ana Paula de Oliveira Marques'; Márcia Carrera Campos Leal'; Anna Karla de Oliveira Tito'; Ilma Kruze Grande de Arruda ${ }^{1}$

\section{Resumo}

O estudo teve por objetivo a formação de grupos operativos como intervenção terapêutica, junto a 101 idosos diabéticos, assistidos na Atenção Básica de Saúde de um município do Nordeste brasileiro. A partir de metodologia pedagógica problematizadora, a intervenção educativa foi estruturada enquanto ferramenta de produção de cuidado e promoção de saúde, incluindo as seguintes etapas constitutivas: análise da demanda - levantamento do conhecimento prévio sobre a temática; pré-análise da problemática do contexto e do grupo - planejamento; levantamento dos temas geradores e definição do foco - execução - e avaliação. Foram identificados seis temas centrais a serem trabalhados: entendendo o diabetes e suas complicações; escolha de alimentos saudáveis convivendo com o diabetes; atividade física e autocuidado com os pés; alimentos diet, light, zero/rótulos; consumo de alimentos saudáveis e preparo e conservação dos alimentos e constituídos 10 grupos operativos acompanhados por seis meses.

Palavras-chave: Envelhecimento. Idoso. Diabetes Mellitus. Educação em Saúde.

\section{Hábitos saudáveis em idosos diabéticos}

A obtenção do equilíbrio energético e a manutenção do peso corporal adequado, mantido por meio do consumo de uma dieta balanceada e da prática regular de atividade física são estratégias importantes na prevenção e tratamento do diabetes mellitus tipo II, enfermidade de prevalência elevada no segmento mais envelhecido da população, com repercussões adversas à saúde do indivíduo e alto custo social (AMERICAN DIABETES ASSOCIATION, 2015). As medidas não farmacológicas apesar de duas vezes mais efetivas, em relação ao tratamento farmacológico isolado, ainda representam um grande desafio na produção do cuidado, no tocante

Professora no Programa de Pós-Graduação em Gerontologia - PPGERO. Departamento de Medicina Social - DMS. Centro de Ciências da Saúde, Universidade Federal de Pernambuco - UFPE. Endereço para correspondência: Campus da Universidade Federal de Pernambuco. Av. Prof. Moraes Rego S/N - CDU - Recife. CEP: 50.739.970. E-mail (na ordem em que aparecem): marquesap@hotmail.com; marciacarrera@hotmail.com; anninhatito@gmail.com; ilmakruze@hotmail.com 
a utilização de estratégias que favoreçam a adesão ao tratamento (BORBA et al, 2011). Modelos tradicionais de educação em saúde, em geral se mostram ineficazes, justificando a necessidade de incorporação de novas abordagens capazes de motivar e sensibilizar os usuários de serviços de saúde para a adoção de hábitos de vida mais benéficos (SALCI et al, 2013). Entre as novas abordagens educativas, destaca-se a metodologia problematizadora e dialógica que valoriza o saber popular, o estímulo e respeito a autonomia do idoso no cuidado de sua própria saúde e incentiva a participação ativa. Como estratégia de educação utilizada nas atividades grupais, o Círculo de Cultura, método proposto por Paulo Freire, possibilita problematizar, estabelecer o diálogo e desvelar diversos temas, capacitando pessoas a refletirem e intervirem na sua própria realidade (BESERRA et al, 2011; HEIDEMANN et al, 2010).

A compreensão do processo educativo em grupos utilizando os Círculos de Cultura representa uma estratégia coletiva de desenvolver a educação em saúde, valorizando o compartilhamento de saberes e o empoderamento de seus integrantes (MACIEL, 2011). O uso desta tecnológica é sugerido nos diversos níveis de produção do cuidado, com destaque para Atenção Básica de Saúde que corresponde a porta de entrada do Sistema Único de Saúde, com resolutividade esperada em torno de $80 \%$ dos problemas a ela demandados. Desta maneira, o estudo teve por objetivo a utilização de grupos operativos como estratégia de intervenção terapêutica para promoção de hábitos saudáveis com idosos diabéticos.

\section{Material e Métodos}

Os idosos que participaram dos grupos operativos $(n=101)$ residiam na Microrregião 4.2 do Município de Recife-PE, estavam cadastrados em uma das Unidades de Saúde da Família (USF) da área, a saber: Cosirof, Engenho do Meio, Macaé, Sinos e Sítio das Palmeiras, eram diabéticos, com diagnóstico registrado nos prontuários de atendimento e não apresentavam comprometimento de cognição e ou comunicação.

A intervenção educativa baseou-se na metodologia pedagógica problematizadora [7] que consiste em: Análise da demanda (levantamento do conhecimento prévio sobre a temática); Pré-análise da problemática do contexto e do grupo (Planejamento); Levantamento dos temas geradores e definição do Foco (Execução) e Avaliação, por meio da verbalização de soluções aplicáveis à realidade dos participantes. $\mathrm{O}$ seu planejamento e organização estiveram baseados em duas etapas: o levantamento do universo temático por parte dos idosos diabéticos e o desenvolvimento das atividades educativas.

Visando uniformizar as temáticas que seriam discutidas nos encontros educativos foi realizado um estudo piloto com 20 idosos diabéticos. A observação e a escuta dos participantes foram efetuadas por meio dos Círculos de Cultura (FREIRE, 2011). Em seguida foram levantadas as estratégias de trabalho em grupo, com valorização das demandas, interesses e aspectos culturais. Os idosos elencaram como estratégias educacionais: filmes, documentários, ilustrações, depoimentos, corte e colagem, jogos lúdicos e atividades com movimento. Para o desenvolvimento dos Círculos de Cultura foi utilizado um roteiro pré-estabelecido. Na condução do processo dialógico participaram um mediador, responsável pela orientação do conteúdo temático, motivação dos participantes, desenvolvimento e conclusão dos debates; e um observador, responsável por 
gravar as falas e realizar o registro das ideias centrais em diário de campo. O material obtido nas gravações foi transcrito na íntegra e utilizado no planejamento das atividades.

\section{Resultados}

Diante das temáticas e dos dispositivos educacionais identificados no grupo piloto e com base na metodologia pedagógica problematizadora foi elaborado um plano de ensino para cada tema central, a saber: 1) Entendendo o diabetes e suas complicações; 2) Escolha de alimentos saudáveis convivendo com o diabetes; 3) Atividade física e autocuidado com os pés; 4) Alimentos diet, light, zero/rótulos; 5) Consumo de alimentos saudáveis e 6) Preparo e conservação dos alimentos. No total foram constituídos 10 grupos operativos, com atividades educacionais planejadas para seis encontros por grupo, com frequência mensal e duração de 2 horas.

Para cada plano educativo as seguintes etapas foram desenvolvidas: dinâmica de sensibilização; problematização; fundamentação teórica; reflexão teórico/prática e elaboração coletiva das respostas; síntese do que foi vivenciado e avaliação, conforme modelo de plano de ensino, apresentado no quadro 1, o qual foi utilizado no primeiro encontro de todos os grupos operativos.

\section{Quadro 1 - Modelo de Plano de Ensino}

Entendendo o diabetes e suas complicações

\begin{tabular}{|c|c|}
\hline Objetivo Geral & $\begin{array}{l}\operatorname{Re}(\text { construir) o conhecimento sobre o diabetes e suas complicações para a promoção } \\
\text { do autocuidado }\end{array}$ \\
\hline \multicolumn{2}{|c|}{ 19Momento: Dinâmica de sensibilização: Personagem importante } \\
\hline Material & Espelho, caixa e chapéu. \\
\hline \multicolumn{2}{|c|}{$\begin{array}{l}\text { Desenvolvimento da dinâmica - Objetivo: Estimular a auto-estima. } \\
\text { Procedimento: um espelho é colado no fundo de uma caixa, posicionada em cima de uma mesa. O facilitador pergunta aos } \\
\text { participantes quem deseja começar e explica que irão ver dentro da caixa a imagem de um personagem muito importante. Cada } \\
\text { participante deverá mencionar duas características do personagem, sem revelar seu nome e dizer se tira o chapéu para esse } \\
\text { personagem. A cada característica o facilitador pergunta aos idosos que ainda não participaram se sabem quem é o personagem. } \\
\text { Ao final, enfatiza que indivíduo tem um papel especial na história da vida e que a participação no grupo pode ser uma experiência } \\
\text { nova e enriquecedora. }\end{array}$} \\
\hline \multicolumn{2}{|c|}{ 2º Momento: Problematização $\quad$ Tempo previsto: 5 min } \\
\hline \multicolumn{2}{|c|}{ Questão Norteadora: O que é o diabetes? Quais as suas complicações? } \\
\hline 30 Momento: Fundamentação Teórica & Tempo previsto: $60 \mathrm{~min}$ \\
\hline 1로 Estratégia educativa & $\begin{array}{l}\text { Vídeo educativo - O que é diabetes? } \\
\text { Link - https://www.youtube.com/watch?v=fITZMH5NLKI }\end{array}$ \\
\hline
\end{tabular}




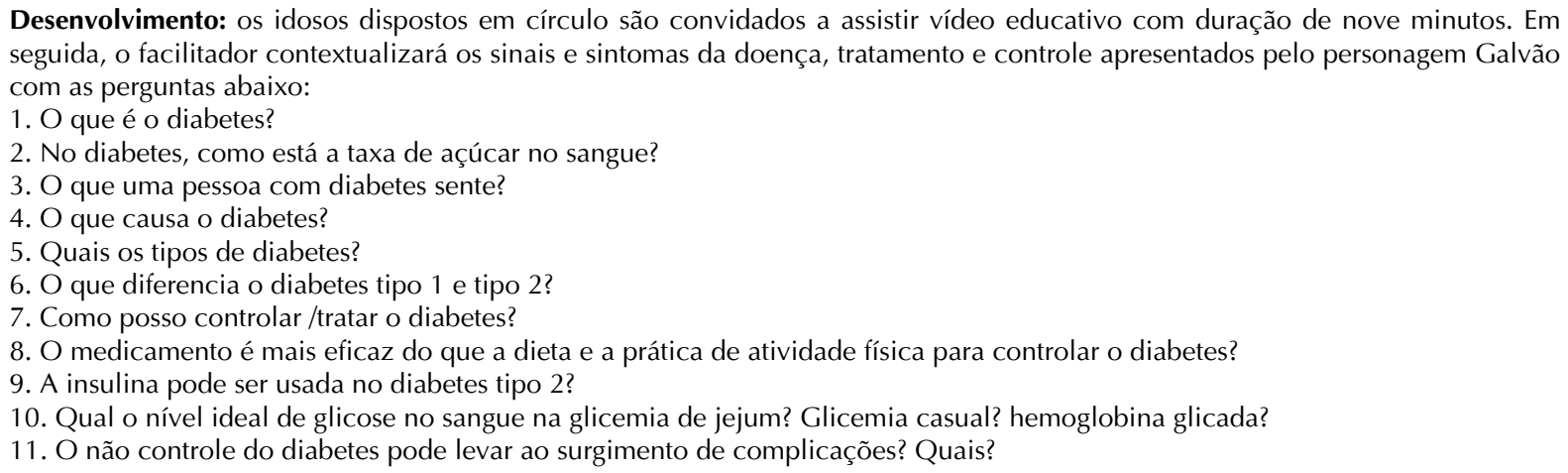

2- Estratégia educativa - Jogo operativo Material - Roleta dividida em seis cores, fichas de cartolina, lápis hidrocor, caixa de Roleta das complicações. papelão.

Desenvolvimento: as peças do jogo serão compostas de uma roleta dividida em seis cores, cada uma, representando uma complicação do diabetes (hipoglicemia, hiperglicemia, retinopatia, nefropatia, neuropatia e pé diabético) e fichas de cartolina com 18 perguntas sobre as complicações. A roleta será colocada no centro do círculo, apoiada em uma mesa e do lado, a caixa de papelão com as fichas separadas por tipo de complicação. Será solicitado a um dos participantes que rode a roleta e a cor da parada da seta indicará o questionamento a ser feito. O facilitador fará a pergunta ao idoso e após sua resposta, a discussão é aberta ao grupo. Em seguida, o idoso sentado, ao lado esquerdo do primeiro participante será convidado a rodar a roleta e o jogo terá continuidade até que todas as perguntas sejam discutidas com o grupo.

\begin{tabular}{|l|l|} 
4- Momento: Reflexão Teórico prática e Elaboração Coletiva das Respostas & Tempo previsto: 5 min \\
\hline Material & Projetor multimídia, Cavalete flip-chart c/quadro branco \\
\hline
\end{tabular}

Situação-Problema. Sr João Batista, 67 anos, chega a USF referindo que a noite sente muita fome e sede. Apresenta formigamento nos pés e nas mãos e visão embaçada. Há 4 meses sofreu uma topada que resultou em uma ferida no dedão do pé que não cicatriza. O enfermeiro faz uma dosagem ponta de dedo no Sr João e o glicosímetro marcou 250 mg/dL. Algumas vezes, faz uso de glibenclamida.

Desenvolvimento. Realização de uma peça com dois componentes da equipe, simulando uma conversa entre dois idosos diabéticos à espera da consulta do Hiperdia na USF com base na situação-problema acima.

5o Momento: Síntese do que foi vivenciado Tempo previsto: $25 \mathrm{~min}$

Desenvolvimento. Após a leitura da situação-problema/encenação teatral, será solicitado aos idosos que identifiquem a sintomatologia do diabetes, a possível presença de complicações e o tratamento seguido para o controle da doença. Os idosos serão estimulados a identificarem ações, a partir de dispositivos presentes na comunidade e na USF para a prevenção e controle dos níveis de glicose.

6o- Momento: Avaliação $\quad$ Tempo previsto: 10 min

Questão - O que foi para o Sr(a) participar do grupo?

Desenvolvimento

Permitirá aos facilitadores identificarem a experiência vivenciada no grupo, com foco no tempo disponível, metodologia e a possibilidade de adotar tais ações no cotidiano de suas vidas.

Continuação Quadro 1 - Modelo de Plano de Ensino

Entendendo o diabetes e suas complicações

\section{Conclusões}

A utilização de metodologias participativas, no processo de educação em saúde, onde a seleção do que será abordado, atende aos interesses e experiências compartilhadas por parte dos que integram o grupo, favorece a construção de um saber coletivo e contextualizado na vivência desses indivíduos, possibilitando maiores chances de adesão a um plano terapêutico.

\section{Agradecimentos}

À Fundação de Amparo à Ciência e Tecnologia de Pernambuco - FACEPE pelo apoio financeiro concedido. 


\section{Promotion of healthy habits with elderly diabetics: use of operative groups as therapeutic intervention}

\section{Abstract}

The study aimed at the formation of operative groups as a therapeutic intervention, together with 101 diabetic elderly, assisted in the Basic Health Care of a city in the Northeast of Brazil. The educational intervention was structured as a tool for the production of care and health promotion, including the following constitutive steps: demand analysis - previous knowledge on the subject; pre-analysis of the context and group problems - planning; survey of the generating themes and definition of the focus - execution - and evaluation. Six main themes were identified: understanding diabetes and its complications; choosing healthy foods while living with diabetes; physical activity and self-care with the feet; diet food, light, zero / labels; consumption of healthy food and food preparation and conservation, and 10 operational groups were set up for six months.

Keywords: Aging. Old man. Diabetes Mellitus. Health education.

\section{Referências}

AMERICAN DIABETES ASSOCIATION. Guidelines Source: Standards of Medical Care in Diabetes - 2015. Diabetes Care, v. 38, suplemento1;38(suppl 1):S1S93,2015.

BESERRA, E. P. et al. Pedagogia freireana como método de prevenção de doenças. Ciência \& Saúde Coletiva, v. 16, suplemento.1, p. 1563-1570, 2011.

BORBA, A.K.O.T; RAMOS, R.S.P.S, MARQUES, A.P.O et al. Educação em saúde: experiência de grupo operativo para idosos diabéticos. Revista de Enfermagem UFPE on line,v.5(spe):2665-71, 2011.

FREIRE, P. A Educação como Prática da liberdade. 34ํㅜ ed. Rio de Janeiro: Paz e Terra, 2011.

HEIDEMANN, I. B. S. et al. Incorporação teórico-conceitual e metodológica do educador Paulo Freire na pesquisa. Revista Brasileira de Enfermagem, v. 63, n. 3, p. 416-420, 2010.

MACIEL, K. F. O. O pensamento de Paulo Freira na trajetória da educação popular. Educação em Perspectiva, v. 2 , n. 2 , p. 326-344, 2011.

SALCI, M. A. et al. Educação em saúde e suas perspectivas teóricas: algumas reflexões. Texto Contexto Enfermagem, v. 22, n. 1, p. 224-30, 2013. 